\title{
Geriatric Oral Health and Its Impact on Eating
}

\author{
Jonathan A. Ship, DMD, ${ }^{*}$ Valerie Duffy, PhD, ${ }^{\dagger}$ Judith A. Jones, DDS, MPH, ${ }^{\ddagger}$ and \\ Susan Langmore, $\mathrm{PhD}^{\mathbb{S}}$
}

\begin{abstract}
OBJECTIVE: Adequate food and fluid intake and nutritional health are requisites for sustaining life. The oral-pharyngeal region has evolved multiple, highly regulated processes to ensure that the intake, chewing, and swallowing of foods and beverages is maintained. The objective of this paper is to identify the independent and collective roles of oral health on eating in older people.
\end{abstract}

DESIGN: Research reports from peer-reviewed scientific journals. Hypothesis-driven research that objectively examined taste, smell, dental and oral mucosal health, dental prostheses, chewing, and swallowing in the context of aging.

DATA EXTRACTION AND SYNTHESIS: Data results were extracted independently by multiple observers. A qualitative synthesis of data results from independent studies was made in order to form conclusions regarding the role of oral health on eating in older people.

CONCLUSIONS: Many oral functions remain intact in healthy older adults. However, significant alterations arise from oral and systemic diseases and their treatments, and these may have a profound effect on eating, drinking, and the nutritional status of older individuals. The care of older persons with smell, taste, dental/alveolar, oral mucosal, chewing, and swallowing problems requires a multidisciplinary team of health care providers. Recognition of the interrelationship between oral, pharyngeal, and systemic physiological processes will help practitioners identify the etiology of these disorders and implement appropriate therapy. J Am Geriatr Soc 44:456-464, 1996.
From the "University of Michigan School of Dentistry, Ann Arbor, Michigan; tUniversity of Connecticut School of Allied Health Professions, Storrs, Connecticut; $\ddagger$ Dental Service, Edith Nourse Rogers VA Medical Center, Bedford, Massa-

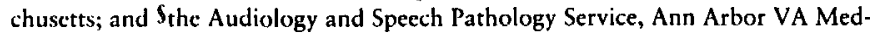
ical Center, Ann Arbor, Michigan.

Address correspondence to Jonathan A. Ship, DMD, Department of Oral Medicine, Pathology, Surgery, University of Michigan School of Dentistry, $1011 \mathrm{~N}$. University, Room 2012, Ann Arbor, MI 48109-1078.
Criti ritical functions of the oral cavity are the intake of foods and beverages, communication, and the protection of the host from noxious substances. Multiple head, neck, and oral tissues have evolved to carry out these vital functions: muscles of facial expression, mastication, and deglutition (including the tongue), oral mucosa, teeth and periodontal tissues, saliva, and taste and smell receptors. These tissues work together continually to keep an individual hydrated and nutritionally healthy, to provide chemosensory information about foods, beverages, and potentially dangerous substances, and to protect the upper aerodigestive tract. While many of these processes and tissues can remain remarkably intact throughout the aging process in healthy persons (Table 1), numerous systemic diseases and their treatment (medications, surgery, head and neck radiation) can cause significant impairments to oral health. These problems can subsequently lead to malnutrition. For example, a recent study examined 200 long-term care older patients, and found that the prevalence of undernutrition was close to $50 \%$, which was associated significantly with eating and swallowing problems, many of them related directly to oral health. ${ }^{1}$ Familiarity with oral/pharyngeal physiological processes in healthy older persons will assist health care providers in their treatment of older patients with multiple, food-related complaints: dehydration, weight loss, malnutrition, difficulty with mastication, dysphagia, impaired smell and taste, and a loss of interest in eating and drinking. This paper reviews taste and smell function, food selection, chewing, and swallowing in older people and discusses how these processes are integrated to protect the nutritional health of older persons.

\section{TASTE AND SMELL IN OLDER PEOPLE}

The chemosensory functions of taste and smell play a vital role in human physiology. They determine the flavor and palatability of foods and beverages, the selection of nutrients essential for life, and the warning of fire, toxic vapors, and spoiled foodstuffs. ${ }^{2}$ The hedonic role of chemosensation is experienced daily by everyone. Alterations in these pleasurable sensations have serious complications for the preservation of oral and systemic health, with dramatic effects on the quality of life. ${ }^{3}$ For example, the inability to detect or distinguish among concentrations of sugar may make it difficult for older diabetic people to control sugar consumption. ${ }^{4}$ Similarly, loss of ability to assess levels of salt accurately may lead hypertensive patients to violate a low-sodium diet. ${ }^{4}$ Since smell and taste provide some of the first sensations during eating, chemosensory disorders can disrupt the mechanisms of eating and drinking, which could place an individual at risk for developing a nutritional imbalance. ${ }^{5}$ Although smell 
Table 1. Oral-Pharyngeal Processes in Older People

\begin{tabular}{|c|c|c|}
\hline Process & $\begin{array}{c}\text { Healthy } \\
\text { Older People }\end{array}$ & $\begin{array}{c}\text { Medically } \\
\text { Compromised }\end{array}$ \\
\hline Taste & Unaffected & Diminished \\
\hline Smell & Diminished & Diminished \\
\hline Food enjoyment & Unaffected & Diminished \\
\hline Salivary output & Unaffected & Diminished \\
\hline Chewing efficiency & $\begin{array}{l}\text { Slightly } \\
\text { diminished }\end{array}$ & Diminished \\
\hline Swallowing & $\begin{array}{l}\text { Slightly } \\
\text { diminished }\end{array}$ & Diminished \\
\hline
\end{tabular}

and taste disorders are relatively common in the general population, ${ }^{6,7}$ they are most likely to exist in older individuals. Increased age per se accounts for some of these disorders, but they are affected more profoundly by numerous systemic diseases, environmental pollutants, and medical treatments including medications, surgery, chemotherapy, and head and neck radiation.

Gustation is subserved by taste buds in the mouth, pharynx, and larynx that are innervated by branches of the facial, glossopharyngeal, and vagus nerves. These taste buds are responsible for four primary sensations: bitter, sweet, salty, and sour. Nongustatory tactile and temperature sensations in the tongue arise from the lingual branch of the trigeminal nerve, and these perceptions interact with gustation and olfaction to discern flavor. Although elevated taste detection thresholds have been detected in older people for several of the primary tastants, ${ }^{4,8}$ many studies have found that intensity perception is virtually age-stable. ${ }^{8}$ Overall, most of the published data indicate that taste is remarkably robust with advancing age and do not support the expectation that most older persons will demonstrate profound taste disturbances.

Olfaction, unlike gustation, is subserved by only one cranial nerve (olfactory), and can detect and discriminate among thousands of different odorants. Mechanoreceptors, thermoreceptors, nociceptors, and proprioceptors from the trigeminal nerve in the mouth and nose provide multiple sensations that assist olfaction and gustation. Whereas the gustatory system is virtually age-stable, olfactory function undergoes significant changes with increasing age. The ability to detect and identify various odorants diminishes markedly across the human life span, ${ }^{5,7-10}$ even in very healthy, nonmedicated subjects. ${ }^{11}$

In addition to the assessment of taste and smell, other studies have evaluated the more complicated problems of flavor perception, ${ }^{12}$ food recognition, ${ }^{5,13}$ and food preference. ${ }^{5,14}$ Although results are not uniform, older individuals do less well when performance is assessed in these tasks. Since taste remains relatively age-stable while smell function declines, ${ }^{15}$ the assessment of complex food stimuli may be impaired in older individuals as a result of olfactory dysfunction.

Medical problems and their treatments have a dramatic influence on taste and smell in older people (Tables 2 and 3). Gustation and olfaction can be altered by damage to peripheral nerves subserving taste and smell systems and central nervous system diseases, ${ }^{16}$ as well as head trauma. ${ }^{17}$ Numerous systemic conditions contribute to chemosensory dysfunc- tion, including neurological, hepatic, renal, endocrine, and ear diseases, nutritional deficiencies, and infections, ${ }^{2,18} \mathrm{De}-$ pression $^{19}$ and other psychiatric diseases ${ }^{20}$ should also be considered in the differential diagnosis of chemosensory problems. The treatments of many systemic conditions have been implicated in both gustatory and olfactory dysfunction. Craniofacial and oral surgery, ${ }^{2}$ chemotherapy, ${ }^{21,22}$ and radiotherapy to the head and neck region ${ }^{22-24}$ cause temporary and/or permanent taste and smell changes. Finally, multiple prescription and nonprescription medications can significantly impair taste and smell perception. ${ }^{18,25}$

Normal chemosensory function cannot operate independently of oral health. Numerous oral conditions can directly or indirectly affect smell and taste by altering the underlying biology of the taste or smell system or by introducing exogenous stimuli that produce abnormal taste or smell sensations in the mouth or nose. ${ }^{26}$ Many oral conditions, including infections, lesions, salivary gland hypofunction, poorly fitting prostheses, and oral manifestations of systemic diseases can cause chemosensory dysfunction. ${ }^{3}$ Therefore, the evaluation of the patient with smell and taste disorders may require a multidisciplinary approach, utilizing several health care providers, because of the complexity of factors affecting the chemical senses.

The complaint of a smell or taste problem may be indicative of a chemosensory disorder, or it could be the manifestation of an oral and/or systemic medical problem. For example, the sudden loss of either smell or taste may be a sign of a brain tumor. Older subjects are more likely to have chemosensory complaints. Unfortunately, these complaints are very poor predictors of olfactory dysfunction ${ }^{11}$ and may be attributable instead to other sensory disturbances or to systemic and cognitive disorders.

In summary, smell and taste function are intricately involved in eating, drinking, nutritional health, and a person's quality of life; chemosensory dysfunction may be indicative of oral and/or systemic disorders; there are prominent age-related declines in olfaction, even in healthy adults; multiple medical conditions and their treatments adversely affect smell and taste; chemosensory dysfunction may increase the risk of malnutrition; and smell and taste complaints are relatively common in older people. Therefore, medical providers caring for older patients should inquire about chemosensory disorders and, when present, identify the cause.

\section{CHEMOSENSORY CHANGES AND FOOD INTAKE IN OLDER PEOPLE}

Taste and smell are important determinants of food selection, especially in older people. ${ }^{27}$ Gustation helps select nutrients (i.e., to satisfy the need for salt or sugar) ${ }^{28}$ whereas olfaction permits the exact identification of a substance ${ }^{29}$ and may play a greater role in the type of foods selected and the pleasure of eating. ${ }^{30}$ Olfactory sensation plays a dual role in the perception of food. ${ }^{31}$ Food odors perceived through the nostrils (orthonasal perception) stimulate appetite and help initiate eating. Once in the mouth, taste, smell from the oral cavity (retronasal perception), and the trigeminal system interact in the perception of food flavor. Individuals are typically unable to separate and distinguish taste from smell in the sensory processing of food. ${ }^{32}$

As outlined above, olfactory perception is more vulnerable to loss with aging than is taste perception. Older people may suffer even greater loss of retronasal olfactory function. 
Table 2. Oral Etiologies of Gustatory and Olfactory Dysfunction, Food Selection, Chewing, and Swallowing Problems

\begin{tabular}{|c|c|c|c|}
\hline Etiology & $\begin{array}{c}\text { Smell and } \\
\text { Taste Problem }\end{array}$ & $\begin{array}{l}\text { Food Selection and } \\
\text { Chewing Problem }\end{array}$ & $\begin{array}{c}\text { Swallowing } \\
\text { Problem }\end{array}$ \\
\hline \multicolumn{4}{|l|}{ Oral Trauma } \\
\hline Burns, lacerations, chemical damage & $x$ & $x$ & $x$ \\
\hline Anesthetic, surgical & $x$ & $\mathrm{x}$ & \\
\hline Removable prosthodontic appliances & $x$ & $x$ & $x$ \\
\hline \multicolumn{4}{|l|}{ Oral Diseases \& Problems } \\
\hline Periodontal diseases & $x$ & $x$ & \\
\hline Dental-alveolar and other infections & $x$ & $x$ & \\
\hline Soft tissue lesions/oral tumors & $\mathrm{X}$ & $x$ & $x$ \\
\hline Candidiasis, denture stomatitis & $\mathrm{x}$ & $x$ & \\
\hline Burning mouth syndrome & $\mathrm{x}$ & $x$ & \\
\hline Salivary dysfunction & $x$ & $x$ & $x$ \\
\hline Tooth loss & & $x$ & $x$ \\
\hline Diminished activity of muscles of mastication & & $x$ & $x$ \\
\hline Impaired chewing & $x$ & $x$ & $x$ \\
\hline Velopharyngeal incompetence & & & $x$ \\
\hline Oral pain & & $x$ & \\
\hline \multicolumn{4}{|l|}{ Treatment of Oral and Systemic Diseases } \\
\hline Oral mouth rinses, gels, \& dentifrices & $\mathrm{x}$ & & \\
\hline Removable prosthodontic appliances & $x$ & $x$ & $x$ \\
\hline Drugs in saliva & $x$ & & \\
\hline Dental material interactions, galvanism & $\mathrm{x}$ & & \\
\hline Poor dental restorations & & $x$ & \\
\hline \multicolumn{4}{|l|}{ Chemosensory Problems } \\
\hline Dysosmia & $x$ & $x$ & \\
\hline Dysgeusia & $x$ & $x$ & \\
\hline Halitosis & $\mathrm{x}$ & $x$ & \\
\hline
\end{tabular}

For example, a direct comparison of orthonasal and retronasal olfaction ${ }^{33,34}$ revealed that some older people tested normosmic on a standard olfactory dysfunction test, but had an elevated retronasal threshold. Active retronasal perception requires adequate manipulation of food to release and transport volatile substances to the olfactory cleft. One study suggested that retronasal perception may be disturbed by the presence of dentures because older women with maxillary dentures had a significantly higher retronasal threshold than those without dentures or with partial dentures only. ${ }^{35}$ This denture effect was staristically independent of measured orthonasal olfaction.

Older persons may show some or a combination of two general nutritional risk patterns, indiscriminate eating and compensation eating, in response to an olfactory loss.

\section{Indiscriminate Eating}

An older person's response to food may be one of indifference as a result of olfactory loss. Inability to perceive the aromas of food can diminish an external cue for eating. When food is perceived as "bland" in flavor, the drive to consume a diverse diet is decreased. ${ }^{36}$ The older person may report a poor food intake, eventually resulting in weight loss or a low body mass index.

The literature provides some support for a pattern of indiscriminate eating in response to olfactory dysfunction. Most individuals who seek treatment for olfactory dysfunction report that food is less flavorful and less enjoyable. ${ }^{37,38}$ In independent-living older people, reports of self-rated fla- vor loss are not consistent, however, and range from only a few older people who notice a loss ${ }^{39}$ to more than $50 \%$ who claim that food has less "taste" than when they were younger. ${ }^{40}$ The report of appetite changes and olfactory dysfunction also vary. One study reported that independent-living older women with olfactory dysfunction did not report a poor appetite or decreased enjoyment of food, but they did indicate less interest in food-related activities (e.g., enjoying cooking for self or others). ${ }^{41}$ Older people with olfactory dysfunction are less discriminating and not as finicky about the foods that they eat. ${ }^{42}$ Finally, it has been suggested that chemosensory losses play a role in the anorexia that is often observed in older people. ${ }^{43}$ Anorexia in response to olfactory loss may be more common in institutionalized older people who may have this loss in combination with additional medical, physical, and psychological dysfunctions.

\section{Compensation Eating}

This can occur when an older person with olfactory dysfunction increases the use of nonolfactory sensory components (e.g., primary taste qualities, food textures) or relies on nonhedonic reasons for eating (e.g., health or social aspects of eating) to compensate for loss of olfactory flavor. Nutritional risks result if the individual compensates with high salt or high sugar foods that often provide excess calories from fat. In fact, persons with olfactory dysfunction often show a risk for obesity. ${ }^{37,38}$

There is data to support the use of compensation eating in response to losses in smell function. The majority of 
Table 3. Systemic Etiologies of Gustatory and Olfactory Dysfunction, Food Selection, Chewing, and Swallowing Problems

\begin{tabular}{|c|c|c|c|}
\hline Etiology & $\begin{array}{c}\text { Smell and } \\
\text { Taste Problem }\end{array}$ & $\begin{array}{l}\text { Food Selection and } \\
\text { Chewing Problem }\end{array}$ & $\begin{array}{l}\text { Swallowing } \\
\text { Problem }\end{array}$ \\
\hline \multicolumn{4}{|l|}{ Upper Respiratory Tract Problems } \\
\hline Lesions of the nose/airway & $x$ & & \\
\hline Viral and bacterial infections & $x$ & & \\
\hline Exposure to toxic airborne contaminants & $\mathrm{x}$ & & \\
\hline \multicolumn{4}{|l|}{ Peripheral or Central Nervous System Pathologies } \\
\hline Head \& neck trauma & $x$ & $\mathrm{x}$ & $\mathrm{x}$ \\
\hline Tumors, lesions & $x$ & & $\mathrm{x}$ \\
\hline Neurological diseases (e.g., Alzheimer's) & $x$ & $x$ & $x$ \\
\hline \multicolumn{4}{|l|}{ Systemic Diseases } \\
\hline \multicolumn{4}{|l|}{ Systemic Conditions } \\
\hline Cerebrovascular diseases & $x$ & $x$ & $x$ \\
\hline Head \& neck cancers & $\mathrm{x}$ & $x$ & $x$ \\
\hline Arthritides & & $\mathrm{x}$ & $\mathrm{x}$ \\
\hline Psychiatric disorders & $x$ & $\mathrm{x}$ & \\
\hline Endocrinopathies (e.g. diabetes) & $x$ & $x$ & $x$ \\
\hline Pulmonary diseases & & & $x$ \\
\hline Gastrointestinal disorders & $\mathrm{x}$ & $x$ & $x$ \\
\hline Swallowing disorders & & $x$ & $x$ \\
\hline Sjögren's syndrome & $\mathrm{x}$ & $x$ & $x$ \\
\hline \multicolumn{4}{|l|}{ Treatment of Systemic Conditions } \\
\hline Prescription \& nonprescription drugs & $\mathrm{X}$ & & $\mathrm{X}$ \\
\hline Head \& neck radiation & $x$ & $\mathrm{x}$ & $x$ \\
\hline Chemotherapy & $\mathrm{x}$ & $\mathrm{x}$ & $x$ \\
\hline Head \& neck surgery & $\mathrm{x}$ & $\mathrm{x}$ & $\mathrm{X}$ \\
\hline Gastrointestinal surgery & & & $\mathrm{x}$ \\
\hline \multicolumn{4}{|l|}{ Nutritional and Dietary Problems } \\
\hline Inappropriately restricted diet & & $\mathrm{x}$ & \\
\hline Monotonous diet, poor texture \& color & & $x$ & \\
\hline Insufficient smell/taste cues to initiate eating & & $\mathrm{x}$ & \\
\hline Nutritional deficiencies & $x$ & $x$ & $\mathrm{X}$ \\
\hline \multicolumn{4}{|l|}{ Psycho-social Problems } \\
\hline Eating alone & & $x$ & \\
\hline Perceived chewing/eating problems & & $\mathrm{x}$ & \\
\hline Low socio-economic status & & $x$ & \\
\hline \multicolumn{4}{|l|}{ Others } \\
\hline Aging & $x$ & $x$ & $\mathrm{x}$ \\
\hline Circadian variation & $x$ & & \\
\hline Menses and pregnancy & $x$ & & \\
\hline Functional problems (ADL, IADL) & & $x$ & \\
\hline
\end{tabular}

individuals who seek treatment for olfactory dysfunction report using foods (e.g., primary tastants, spices, and trigeminal stimulants) and non-food related strategies (e.g., eating with others) to maintain food appreciation. ${ }^{37}$ If smell function is altered, the primary taste component (sweet, sour, bitter, salty) may become more apparent because of the lack of modulation of tastes via olfaction. This can result in changes in food preference and food intake. Independentliving older women with diminished olfactory perception showed lower preference for foods with a strong sour/bitter taste (i.e., citrus fruits, Brassica vegetables), ingested sugars and high-fat sweets more frequently, and consumed a cardiac-risk nutrient intake (higher intake of saturated fatty acid calories, lower polyunsaturated to saturated fatty acid intake, higher total fat). ${ }^{41}$

Older institutionalized individuals with olfactory dysfunction may be at the greatest risk of developing nutritional problems. They may be on restricted diets, prohibiting them from using the primary tastes to compensate for olfactory changes. In addition, chewing difficulties can limit textural diversity, a food attribute highly valued by individuals with congenital anosmia. ${ }^{44}$ Many caregivers use creative methods to enhance the visual display of texture-modified foods. Schiffman and Warwick ${ }^{45}$ advocated the use of flavor enhancers to counteract taste and smell deficits and to maintain nutritional status. Older persons provided higher preference ratings for moderately amplified foods than did younger persons. ${ }^{45}$ Although older people may not recognize the olfactory decline, they are capable of recognizing flavor improvement caused by odor fortification. Finally, eating in a social atmosphere can draw a person's attention away from food flavor and enhance the enjoyment of the meal.

In summary, the nutritional risks associated with chemosensory and eating problems are not uniform and, therefore, 
require individualized oral and medical evaluations and counseling to restore nutritional health and food enjoyment. The perception of a nutritional and/or a chemosensory disorder may aid clinicians in determining the course of treatment. For example, perceived chewing difficulty with a dental prosthesis was a larger determinant of food acceptance than measured function. ${ }^{46}$ In a group of patients who sought treatment for chemosensory dysfunction, there was greater nutritional risk in individuals who claimed that the disorder changed their interest in eating or felt that eating exacerbated the disorder. ${ }^{47}$ The perception of olfactory problems may increase the risk of nutritional problems even in the absence of objectively measured dysfunction. ${ }^{35}$ Therefore, a comprehensive stomatological ${ }^{3}$ and physical examination, ${ }^{48,49}$ which includes smell function tests, ${ }^{50}$ in patients with eating complaints may help determine if the etiology is physiological or the manifestation of behavioral and/or psychosocial factors.

Treatment of smell dysfunction and eating disorders should be directed toward the identified cause (Tables 2,3 ) if the cause can be determined. In addition, strategies should be implemented that capitalize on nonolfactory components of food flavor (altering food texture, primary taste qualities, temperature, and color) to help maintain food enjoyment. Foods and beverages that are salty, sweet, or that stimulate the trigeminal nerve (e.g., black or red pepper, carbonation) may provide another dimension to the eating experience. Enhancing the olfactory component of food flavor can also improve food intake in patients with olfactory dysfunction. These compensatory strategies may help improve dietary choices and maintain both food enjoyment and nutritional health.

\section{CHEWING IN OLDER PEOPLE}

Effective mastication requires the use of many specialized tissues of the oro-facial region, including the muscles of mastication and the tongue, as well as teeth, periodontium, saliva, healthy oral mucosa, and intact neuromuscular coordination. ${ }^{51}$ There are three major issues affecting chewing in older people and its impact on dietary choices: (1) the relationships between age, dentition status, and masticatory effciency; (2) the connection between objectively measured chewing function, perceived ease of chewing, and food preferences; and (3) the affect of age and changes in dentition status on nutrition, morbidity, and mortality.

National data demonstrate that older people are more likely than any other age group to have lost some or all of their teeth. ${ }^{52-54}$ At the same time, the concept that tooth loss is not a consequence of normal aging has gained acceptance among health professionals. ${ }^{55}$ Currently, tooth loss is viewed as the result of an accumulation of insults to the teeth and periodontium. Over the course of a human life span, older persons have been exposed to more trauma and diseases involving the dento-alveolar complex than persons in other age groups just by virtue of their longevity. Therefore, older persons are more likely to be totally or partially edentulous than other age groups. ${ }^{52,54,56}$

A substantial body of evidence indicates that tooth loss affects objective measures of masticatory performance. ${ }^{57-61}$ Investigations in the 1950 s and 1960 s suggested that masticatory efficiency in wearers of complete dentures was approximately $75 \%$ lower compared to an intact natural dentition. ${ }^{6-65}$ More recent work indicates that the diminished masticatory efficiency caused by tooth loss may be 30 to $40 \% .^{66,67}$ However, these discrepancies may be partially related to differences in test foods, research methodologies, and subject populations.

The influence of age on masticatory efficiency is less clearly understood. Studies conducted by the Boston VA Dental Longitudinal Study (DLS) demonstrated that when raw carrots were used as a test food, dentition status (denture wearers vs persons with intact natural dentition) rather than age was the primary determinant of masticatory ability. ${ }^{68-70}$ In addition, older subjects, regardless of dentition status, chewed their food longer and with more strokes than younger individuals. A longitudinal assessment of masticatory effciency in DLS subjects showed that there were clinically small but statistically significant age-related changes in swallowing threshold indexes among persons with natural teeth but not among denture wearers. ${ }^{71}$ In contrast, a cross-sectional study using almonds as a test food showed that both dentition status and age affected chewing performance as well as swallowing threshold tests. ${ }^{67}$ In addition to age and dentition effects on mastication, oral motor performance is affected to a modest degree by aging, ${ }^{72}$ which could have deleterious consequences to chewing performance in older people. Finally, a recent investigation reported that anterior masseter muscle size was significantly greater in dentate individuals compared with edentulous individuals; this relationship was independent of the age of the individual. ${ }^{73}$

While it is difficult to generalize about total chewing capacity based on these limited findings, they suggest that dentition, not age per se, has a direct influence on mastication. As discussed previously, dentition status is related to age not because of the aging process but rather as a result of the increased length of time during which insults to the dentition accumulate. Dentition status is subsequently related to chewing performance, as measured by masticatory efficiency and swallowing threshold. Persons with intact natural dentition perform more efficiently than those with compromised natural dentition, partial dentures, and complete dentures. Further, age influences how long a person chews, measured both in time and number of strokes. However, there are wide variations according to dentition status, and the relationship between age and masticatory efficiency may vary with the type of food consumed.

Masticatory ability clearly affects food preferences, perceived ease of chewing, taste and texture acceptability, and frequency of ingestion of hard to chew items (e.g., carrots and other crunchy raw vegetables, crunchy breads). $5,68,69,71,74-76$ Furthermore, denture wearers are more likely to have a poorer quality diet than persons with natural teeth. ${ }^{77}$ It is not clear, however, how these diet alterations affect nutrition adequacy as measured by anthropometric, biochemical, and clinical measures of nutrition. Sullivan et al ${ }^{78}$ demonstrated recently that the number of oral problems was the single most important predictor of weight loss in a group of frail older people. In addition, denture wearers perceive their dentures as interfering with chewing ability. ${ }^{79,80}$

A key relationship that requires investigation is that of tooth loss, nutrition, and general health. While oral diseases can exacerbate systemic conditions (e.g., diabetes), it is not known to what extent tooth loss and dental disease by themselves can adversely affect the nutritional health of an older person. Furthermore, poor nutritional status can have a deleterious effect on oral health. ${ }^{81}$ It has been established that 
edentulism may profoundly affect food selection and nutritional status, but it is not clear if these alterations are sufficient to cause significant morbidity and mortality. Edentulism may predispose a person to difficulties chewing, yet good nutrition is quite possible in the absence of teeth given the wide variety of dietary supplements available today.

It is possible that good oral health status, including an intact natural dentition, is a marker for successful aging. However, one study utilizing ambulatory, generally healthy adults found no overall oral health differences between nonmedicated subjects not being treated for medical problems and individuals taking medications and being treated for medical problems. ${ }^{82}$ Nevertheless, preventive health habits probably contribute to sustained good overall health.

Finally, decrements in chewing can limit the variety and pleasure associated with eating. For these reasons, the effects of tooth loss may be more measurable from a quality of life perspective rather than through the use of physiologic measures. This is particularly important in the care of an older person, when quality of life issues may have greater significance than quantity of years yet to live. Future research in this area should endeavor to assess the impact of dentition status in a multidimensional fashion, including objective measures of dental and oral health and markers of patients' perceived quality of life.

\section{SWALLOWING IN OLDER PEOPLE}

Once food is selected, put in the mouth, tasted, and chewed, the act of swallowing completes the process. Although the conscious awareness of ingestion stops at chewing, the neurological system continues to direct the process whereby the bolus moves from the mouth, through the throat and esophagus, terminating at the stomach. Swallowing occurs in three stages: the oral stage, the pharyngeal stage, and the esophageal stage. Each of these must work adequately to ensure a safe and efficient swallow.

The oral stage consists of two components: the preparatory phase, where food or liquid is manipulated in the oral cavity, and the initiation phase, where the bolus is thrust into the pharynx to initiate the swallow. During the preparatory stage, multiple factors are necessary to facilitate mastication and posturing of the bolus: adequate dentition, masticatory muscle strength, labial and buccal mucosal tone and strength, tongue coordination and mobility, saliva, and intact taste, thermal and tactile sensations. The bolus must be contained within the oral cavity while it is manipulated, chewed, and then transported to the back of the tongue for the swallow.

The transition from the oral preparatory stage to the initiation phase has not been well characterized. A recent report suggested that the consistency of the food bolus in the mouth determines when swallowing will begin and concluded that sensory input from oral cavity receptors may be critical for triggering the swallow reflex. ${ }^{83} \mathrm{~A}$ portion of chewed food is transported into the oropharynx during mastication, after which a swallow is initiated. Swallowing foods always occurs during the phase in mastication where the teeth are closest together, whereas liquids are swallowed without an intervening transport cycle.

The most critical oral structure for initiating a brisk and effective swallow is the tongue. Just before thrusting the bolus into the pharynx, the tongue moves the bolus into position by means of a 'tipper' or 'dipper' movement. ${ }^{84}$ The most common pattern is the tipper, where the tip of the tongue presses against the incisors and the bolus is held against the palate. A second pattern, more prevalent in older subjects, is the dipper pattern, where part of the bolus is held beneath the tongue initially, and the tongue tip must dip beneath the bolus to carry it to the supralingual position seen in the tipper pattern. Once the entire bolus is positioned above the tongue, the tongue elevates and rolls posteriorly to deliver the bolus to the pharynx.

The pharyngeal stage of the swallow technically begins when the bolus passes over the tongue and enters the pharynx. However, there is considerable overlap of pharyngeal/ laryngeal movements with oral movements. When the bolus is still in the mouth, the larynx begins to elevate and move anteriorly to make room for the bolus, and the airway begins to close to prevent aspiration. The pharyngeal stage is more programmed than the oral stage. Regardless of the size or consistency of the bolus, an invariant order of events occurs, including airway closure, velar elevation, laryngeal elevation, pharyngeal shortening, opening of the upper esophageal sphincter, and pharyngeal contraction. Respiration ceases during the swallow.

As the bolus is propelled through the pharynx and into the esophagus, the last stage in swallowing begins. The bolus falls through the esophagus by gravity and is assisted by a strong peristaltic wave. While it takes only about 1 second for the bolus to pass from the anterior faucial pillars through the cricopharyngeus into the esophagus, the bolus requires approximately 10 seconds to traverse the entire esophagus. The lower esophageal sphincter relaxes as the bolus approaches it to allow passage into the stomach.

Normal aging has been reported to have some minor adverse effects on swallowing, although in the healthy older person, advanced age per se does not appear to cause any clinical dysfunction ${ }^{85,86}$ The changes are caused by sensory, muscular, and neurological deterioration that occur with age and are manifest throughout the body.

Two studies have reported age differences that relate to tongue force and pressure exerted at the initiation of the swallow. Robbins et al. ${ }^{87}$ found that maximum tongue force was reduced in older persons, but the force utilized during swallowing was not different from younger persons. Conversely, Perlmann et al. ${ }^{88}$ demonstrated that older subjects generated higher oropharyngeal pressures during swallowing and held the pressure longer than did the younger subjects. Methodological differences may account for these discrepant findings.

Older subjects often have a delayed initiation of the swallow: the swallow does not begin until after the bolus passes a key trigger point in the oropharynx ${ }^{85,86,89}$ Robbins et al. ${ }^{85}$ reported an increase in laryngeal penetration in older subjects (the material entered the laryngeal vestibule), but Tracy et al. ${ }^{86}$ reported no difference among the age groups in this regard. Significantly, the occurrence of aspiration (passage of the bolus below the vocal folds into the trachea) has not been documented in healthy older persons.

Esophageal motility also declines with aging, resulting in longer transit time and less efficient peristalsis. ${ }^{90}$ In addition, gastroesophageal reflux disease is more prevalent in older people. ${ }^{91,92}$ As with the pharyngeal stage of swallowing, these changes are generally reported to be minor, and have not been clinically associated with dysphagia. ${ }^{93}$

The most common causes of oropharyngeal dysphagia in older people (Tables 2,3 ) are cerebrovascular and neurolog- 
ical diseases (e.g., Parkinson's disease, multiple sclerosis, motor neuron disease, and Alzheimer's disease) that affect the muscles used in swallowing. Head and neck cancer has a dramatic affect on swallowing attributable to surgical resection of vital structures and/or radiation therapy that destroys salivary glands and causes laryngeal and pharyngeal fibrosis. Other systemic diseases, including arthritis, diabetes, and pulmonary disease, may also cause dysphagia.

The effect of these diseases on the oral and pharyngeal stages of swallowing are multiple and complex. Diseases that affect strength, speed, and/or coordination of cranial nerve musculature often result in a slow and weak swallow. In such cases, the tongue cannot manipulate the bolus efficiently, mastication is inadequate, and the initiation of the swallow is delayed and weak. As a result, much of the bolus is not cleared out of the mouth during the swallow and is also left as residue in the pharynx. If laryngeal airway closure is weak or slow, or if the residue is substantial, aspiration may occur, with the bolus falling below the larynx into the trachea and lungs.

The adverse effect of impaired dental health on swallowing in older people is probably most apparent when considering chewing (see previous discussion). However, poor oral/ dental health may also affect swallowing. Dentures have a significant impact on oral sensation, oral stereognosis, and taste. ${ }^{94-97}$ The change in sensation caused by an oral prosthesis may affect the initiation of the swallow because sensory input from the periphery is known to be an important factor in "priming" the swallowing center in the brainstem for a swallow response. ${ }^{83,94}$ One study has provided some support for this hypothesis. Tallgren and Tryde found that edentulous patients who were provided with a complete upper denture manifested changes in swallowing duration 2 years after first use of the prosthesis. ${ }^{94}$ The clinical significance of this finding remains to be studied.

Although salivary gland function appears to be relatively unimpaired in healthy older persons, ${ }^{98-100}$ multiple medical problems and their treatments (medications, head and neck radiation) cause salivary gland dysfunction and the complaint of a dry mouth (xerostomia) in older people. ${ }^{101}$ Diminished salivary secretions have an adverse effect on many oral functions, including chewing, tasting, and swallowing. For example, Sjogren's syndrome, an autoimmune exocrinopathy affecting primarily postmenopausal females, causes the destruction of salivary glands, and there is a consequent delay in the initiation of swallowing. ${ }^{102,103}$ Older patients with salivary gland disorders and xerostomia attributable to multiple medications are more likely to complain of dysphagia ${ }^{104}$ and may be at risk for developing aspiration pneumonia. ${ }^{105}$

Treatment for dysphagia can be medical, surgical, or behavioral in nature. Primary providers are usually physicians, speech-language pathologists, dentists, nurses, dieticians, and occupational therapists. The complications of this problem are serious, including aspiration pneumonia, malnutrition, dehydration, and the possible extension of diseases such as esophageal cancer. Therefore, early identification, and appropriate diagnosis and management are critical for patients with dysphagia.

\section{SUMMARY}

Adequate food intake and nutritional health are requisites for sustaining life. The oral-pharyngeal region has evolved multiple, highly regulated processes to ensure that the intake, chewing, and swallowing of foods and beverages is maintained. Many of these functions remain intact in healthy older adults; however, significant alterations may have a profound effect in older, medically compromised individuals. The care of older persons with smell, taste, oral, chewing, and swallowing problems requires a multidisciplinary team of health care providers. Recognition of the interrelationship between oral, pharyngeal, and systemic physiological processes will help practitioners identify the etiology of these disorders and implement appropriate therapy.

\section{REFERENCES}

1. Kcller HH. Malnutrition and institutionalized elderly: How and why? J Am Geriatr Soc 1993;41:1212-1218.

2. Deems DA, Doty RL, Settle RG et al. Smell and taste disorders: A study of 750 patients from the University of Pennsylvania smell and taste center. Arch Otolaryngol Head Neck Surg 1991;117:519-528.

3. Ship JA. Gustatory and olfactory considerations: Examination and treatment in general practice. J Am Dent Assoc 1993;124:55-62.

4. Schiffman SS. Perception of taste and smell in elderly persons. Crit Rev Food Sci Nutr 1993;33:17-26.

5. Murphy C. Nutrition and chemosensory perception in the elderly. Crit Rev Food Sci Nutr 1993;33:3-15.

6. National Ambulatory Medical Care Survey. In: Report of the Panel on Communicative Disorders to the National Advisory Neurological and Communicative Disorders and Stroke Council. Washington, DC: Public Health Service, NIH Publication No. 81-1914, June 1, 1979.

7. Wysocki CA, Gilbert AN. National Geographic Smell Survey: Effects of age are heterogenous. Ann N Y Acad Sci 1989;561:12-28.

8. Weiffenbach JM, Bartoshuk LM. Taste and smell. Clin Geriatr Med 1992;8:543-555.

9. Doty RL, Shaman P, Dann MS. Development of the University of Pennsylvania smell identification test: A standardized microencapsulated test of olfactory function. Physiol Behav 1984;32:489-502.

10. Stevens JC, Cain WS. Old-age deficits in the sense of smell as gauged by thresholds, magnitude matching, and odor identification. Psychol Aging 1987;2:36-42.

11. Ship JA, Weiffenbach JM. Age, gender, medical treatment, and medication effects on smell identification. J Gerontol 1993;48:M26-32.

12. de (iraaf C, Polet $P$, van Staveren WA. Sensory perception and pleasantness of food flavors in elderly subjects. J Gerontol 1994;49:P93-99.

13. Schiffman SS. Food recognition by the elderly. J Gerontol 1977;32:586592.

14. Murphy C. Age-related effects on the threshold, psychophysical function and pleasantness of menthol. J Gerontol 1983;38:217-222.

15. Stevens JC, Bartoshuk L.M, Cain WS. Chemical senses and aging: Taste ver sus smell. Chem Senses 1984;9:167-179.

16. Esiri MM. Pathology of the olfactory and taste systems. In: Getchell TC, Doty RL, Bartoshuk L.M, Snow JB Jr., eds. Smell and Taste in Health and Disease. New York: Raven Press, 1991, pp 683-701.

17. Costanzo RM, Zasler ND. Head trauma. In: Getchell TC, Doty RL, Bartoshuk LM, Snow JB Jr., eds. Smell and Taste in Health and Disease. New York: Raven Press, 1991, pp. 711-730.

18. Schiffman SS. Taste and smell in disease. N Engl J Med 1983;308:1275$1279,1337-1343$.

19. Miller SM, Naylor G]. Unpleasant taste-A neglected symptom in depression. J Affect Disord 1989;17:291-293.

20. Doty RL, Bartoshuk LM, Snow JB Jr. Causes of olfactory and gustatory disorders. In: Getchell TC, Doty RL, Bartoshuk LM, Snow JB Jr., eds. Smell and Taste in Health and Discase. New York: Raven Press, 1991, pp $449-462$.

21. Lockhart PB, Clark JR. Oral complications following neoadjuvant chemotherapy in patients with head and neck cancer. Natl Cancer inst Monogr 1990;9:99-101.

22. Beidler L.M, Smith JC. F.ffects of radiation therapy and drugs on cell turnover and taste. In: Getchell TC, Doty RL, Bartoshuk LM, Snow JB Jr., eds. Smell and Taste in Health and Diseasc. New York: Raven Pressk, 1991, pp 753-763.

23. Rothwell BR. Prevention and treatment of the orofacial complications of radiotherapy. J Am Dent Assoc 1987;114:316-322.

24. Mossman KL. Gustatory tissue injury in man: Radiation dose response relationships and mechanisms of taste loss. Br J Cancer 1986;53(suppl): S9-11. 
25. Schiffman SS. Drugs influencing taste and smell perception. In: Getchell TC, Doty RL, Bartoshuk LM, Snow JB Jr., eds. Smell and Taste in Health and Disease. New York: Raven Press, 1991, pp 845-850.

26. Catalanotto FA, Sweency EA. Oral conditions affecting chemosensory function. In: Getchell TC, Doty RL, Bartoshuk LM, Snow JB Jr., eds. Smell and Taste in Health and Disease. New York: Raven Press, 1991, pp 643-651.

27. Krondl MM, Lau D, Yurkiw MA, Coleman PH. Food use and perceived food meanings of the elderly. J Am Diet Assoc 1982;80:523-529.

28. Bartoshuk L. Taste, smell, and pleasure. In: Bolles R, ed. The Hedonics of Taste. Hillsdale, NJ: Lawrence Erlbaum Associates, Inc., 1991, pp 15-28.

29. Cain WS. Taste vs smell in the organization of perceptual experience: Consequences for food acceptability. In: Solms J, Booth D, Pangborn R, Raunhardt O, eds. Chemical Composition and Sensory Properties of Foods and Their Influence on Nutrition. New York: Academic Press, 1987, pp 63-77.

30. Shepherd R. Sensory influences on salt, sugar and fat intake. Nutr Res Rev 1988;1:125-144.

31. Rozin P. "Taste-smell confusions" and the duality of the olfactory sense. Percept Psychophys 1982;:31:397-401.

32. Murphy C, Cain WS, Bartoshuk LM. Mutual action of taste and olfaction. Sens Processes 1977;1:204-211.

33. Duffy VB. Olfactory dysfunction, food behaviors, dietary intake, and anthropometric measures in single-living, elderly women. Storrs, CT: University of Connecticut, 1992, Thesis.

34. Duffy VB, Cain W, Stevens J, Ferris A. A test of flavor sensitivity. Chem Senses $1991 ; 16: 516-517$.

35. Duffy VB, Ferris A, Cain W. Lower olfactory functioning associates with nutritional risk in elderly women. Chem Senses 1993;18:549.

36. Rolls $B$, McDermott $T$. Effects of age on sensory-specific satiety. Am J Clin Nutr 1991;54:988-996.

37. Ferris AM, Duffy VB. The effect of olfactory deficits on nutritional status: Does age predict individuals at risk? Ann N Y Acad Sci 1989;561:113-123.

38. Mattes $R$, Cowart B. Dietary assessment of patients with chemosensory disorders. J Am Diet Assoc 1993:94:50-56.

39. Stevens J. Food quality reports from noninstitutionalized aged. Ann N Y Acad Sci 1989;561:87-93.

40. Todhunter EN. Life style and nutrient intake in the elderly. ln: Winick $M$, ed. Nutrition and Aging. New York: John Wilcy, 1976, pp 119-127.

41. Duffy VB, Backstrand J, Ferris A. Olfactory dysfunction and related nutri tional risk in frec-living, elderly women. J Am Diet Assoc 1995;95:879884.

42. Schiffman $S$, Warwick $Z$. Use of flavor-amplified foods to improve nutritional status in elderly persons. Ann N Y Acad Sci 1989;561:267-276.

43. Pelchat M, Stoess C. Aging, olfaction and food preferences. Chem Senses (Abstract) 1991:16:567.

44. Doty $R$. Food preference ratings of congenitally anosmic humans. In: Kare M, Maller O, eds. Chemical Senses and Nutrition. New York: Academic P'ress, 1977, pp 315-325.

45. Schiffman S, Warwick Z. Fffect of flavor enhancement of foods for the elderly on nutritional status: Food intake, biochemical indices, and anthropometric measures. Physiol Behav 1993;53:395-402.

46. Wayler AH, Muench MF, Kapur KK, Chauncy HH. Masticatory performance and food acceptability in persons with removable partial dentures, full dentures, and intact natural dentition. J Gerontol 1984;39:284-289.

47. Mattes R, Cowart B, Schiavo $M$ et al. Dietary cvaluation of patients with smell and/or taste disorders. Am J Clin Nutr 1990;51:233-240.

48. Snow JB Jr, Doty Rl, Bartoshuk LM. Clinical evaluation of olfactory and gustatory disorders. In: Getchell TC, Doty RL, Bartoshuk I.M, Snow JB Jr. eds. Smell and Taste in Health and Diseasc. New York: Raven Press, 1991, pp 46.3-470.

49. Bartoshuk I.M, Cient J, Catalanotto FA, Goodspeed RB. Clinical evaluation of taste. An J Otolaryngol 1983;4:257-260.

50. Doty RI, Shaman P, Applehaum SI. et al. Smell identification ability: Changes with age. Science 1984;226:1441-144.3.

51. Baum BJ, Ship JA. The oral cavity. In: WR Hazzard et al., eds. Principles of Geriatric Medicine and Gerontology, 3rd Ed. New York; McGraw-Hill, 1993, pp 431-439.

52. National Institute of Dental Research. Oral Health of United States Adults: The National Survey of Oral Health in U.S. Employed Adults and Seniors: 1985-86. National Findings. Bethesda, MD: National Institutes of Health, NIH Publication No. NIH-87-2868, 1987.

53. Bloom B, Gift HC, Jack SS. National Center for Health Statisties, Dental Services and Oral Health: United States, 1989. Vital and Health Statistics, Series 10, No. 183, Hyattsville, MD: DHHS Publication No. PHS-931511 .

54. Brown LJ. Trends in tooth loss among US employed adults from 1971 to 1985. J Am Dent Assoc 1994;125:5.33-540.
55. Baum BJ. Research on aging and oral health: An assessment of current status and future needs. Spec Care Dentist 1981;1:156-165.

56. Douglass $\mathrm{CW}$, Jette $\mathrm{AM}$, Fox $\mathrm{CH}$ et al. Oral health status of the elderly in New England. J Cierontol 1993;48:M39-46.

57. Manly RS. The effect of dental deficiency on mastication and food preference. Oral Surg Oral Med Oral Pathol 1950;3:674-685.

58. Helkimo F, Carlsson CE, Helkimo M. Chewing efficiency and state of dentition. Acta Odontol Scand 1978;36:33-41.

59. Osterberg I, Steen B. Relationship between dental state and dietary intake in 70-year-old males and females in Goteborg, Sweden: A population study. J Oral Rehabil 1982;9:509-521.

60. Chauncey IHH, Kapur KK, Feller RP, Wayler AH. Altered masticatory function and perceptual estimates of chewing experience. Spec (are Dentist 1981;1:250-2.55.

61. Chauncey HH, Muench ME, Kapur KK, Wayler AH. The effect of the loss of tecth on diet and nutrition. Int Dent J 1984;34:98-104.

62. Manly RS, Braley LC.. Masticatory performance and efficiency. J Dent Res $1950 ; 29: 448-462$.

63. Manly RS, Vinton P. A survey of the chewing ability of denture wearers. J Dent Res 1951;30:314-321.

64. Kapur KK. Soman SD. Masticatory performance and efficiency in denture wearers. J Prosthet Dent 1964;14:687-697.

6.5. Yurkstas AA. The effect of missing teeth on masticatory performance and efficiency. J Prosthet Dent 1954;4:120-123.

66. Gunne H-SJ. Masticatory efficiency and dental state. A comparison between two merhods. Acta Odontol Scand 1985:43:139-146.

67. Idowu AT, Graser CiN, Handelman SL. The effect of age and dentirion status on masticatory function in older adults. Spec Care Dentist 1986;6:808.3.

68. Wayler AH, Kapur KK, Feldman RS, Chauncey IIH. Effects of age and dentition status on measures of food acceptability. J Gerontol 1982;37:294-299.

69. Wayler AH, Chauncey HH. Impact of complete dentures and impaired nat ural dentition on masticatory performance and food choice in health aging men. I Prosthet Dent 1983;49:427-433.

70. Feldman RS, Kapur KK, Alman JE, Chauncey HH. Aging and mastication: Changes in performance and in the swallowing threshold with natural dentition. J Am Geriatr Soc 1980;28:97-103.

71. Feldman RS, Alman J, Muench ME, Chauncey HH. Longitudinal stability and masticatory function of human dentition. Gerodontology 1984;3:107113.

72. Baum BJ, Bodner L. Aging and oral motor function: Evidence for altered performance among older persons. J Dent Res 1983;62:2-6.

73. Kasai K, Richards I.C, Kanazawa E et al. Relationship between attachment of the superficial masseter muscle and craniofacial morphology in dentate and edentulous humans. J Dent Res 1994;73:1142-1149.

74. Sandstrom B, lindquist $\mathrm{LW}$. The effect of different prosthetic restorations on the dictary selection of edentulous patients. Acta Odontol Scand 1987:45:42.3-428.

75. Yurkstas AA, Emerson WH. Dictary sclections of persons with natural and artificial teeth. J Prosthet Dent 1964;14:695-697.

76. Hartsook E. Food selection, dietary adequacy and related dental problems of patients with dental prostheses. J Prosthet Dent 1974;32:32-40.

77. Papas A, Palmer C:, Rounds M. Denture status and nutrition in the elderly. J Dent Res (Abstract) 1988;67:267.

78. Sullivan DI, Martin W, Flaxman N, Hagen JE. Oral health problems and involuntary weight loss in a population of frail elderly. J Am Cicriatr Soc $1993 ; 41: 72.5-731$

79. Kressin N, Jones J, Hayes C et al. Oral health status and quality of life. J Dent Res (Abstract) 1995;74:168.

80. Agerberg G, Carlsson GE. Chewing ability in relation to dental and general health. Analyses of data obtained from a questionnaire. Acta Odontol Scand 1981;39:147-153.

81. P'a GW. Oral health and nutrition. Prim Care 1994:21:121-133.

82. Ship JA, Baum BJ. Old age in health and disease. Lessons from the oral cavity. Oral Surg Oral Med Oral Pathol 1993;76:40-44.

83. Palmer JB, Rudin NJ, Ciustavo L, Crompton AW. Coordination of mastication and swallowing. Dysphagia 1992;7:187-200.

84. Dodds WJ, Taylor AJ, Stewart ET et al. Tipper and dipper types of oral swallows. Am J Roentgenol 1989;153:1197-1199.

85. Robbins J, Hamilton JW, Lof GL, Kempster GB. Oropharyngeal swallowing in normal adults of different ages. Gastroenterology 1992;103:823829.

86. Tracy JF, Logemann JA, Kahrilas PJ et al. Preliminary observations on the effects of age on oropharyngeal deglutition. Dysphagia 1989;4:90-94.

87. Robbins J, Ievine R, Wood J et al. Age effects on lingual pressure as a risk factor for dysphagia. J Gerontol 1995;50A:M257-262. 
88. Perlmann AL, Schultz J, VanDaele DJ. Fffects of age, gender, bolus volume, and bolus viscosity on oropharyngeal pressure during swallowing. J Appl Physiol 1993;75:33-37.

89. Sonies BC, Parent L.J, Morrish K, Baum BJ. Durational aspects of the oralpharyngeal phase of swallowing in normal adults. Dysphagia 1988;3:1-10.

90. Mandelstam P, Lieber A. Cineradiographic evaluation of the esophagus in normal adults. Gastroenterology 1970;58:32-38.

91. Dodds WJ, Hegan WJ, Helm JF, Dent J. Pathogenesis of reflux esophagitis. Gastroenterology 1981;81:376-394.

92. Pries JM. Coping with reflux esophagitis in the aged. Geriatrics 1982;37:57-67.

93. Ergun GA, Miskovitz PF. Aging and the esophagus: Common pathologic conditions and their effect upon swallowing in the geriatric population. Dysphagia 1992;7:58-63.

94. Tallgren A, Tryde G. Chewing and swallowing activity of masticatory muscles in patients with a complete upper and lower partial denture. J Oral Rehabil 1991;18:28.5-299.

95. Manly RS, Pfaffman C, Lathrop DD, Keyser J. Oral sensory thresholds of persons with natural and artificial dencitions. J Dent Res 1952;31:305-312.

96. Litvak H, Silverman SI, Garfinkel L. Oral stereognosis in dentulous and edentulous subjects. J Prosthet Dent 1971;25:139-151.
97. Henkin RI, Christianson RL. Taste thresholds in patients with dentures. J Am Dent Assoc 1967;75:118-120.

98. Ship JA, Baum BJ. Is reduced salivary flow normal in old people? Lancet 1990;336:1507.

99. Wu AJ, Atkinson JC, Fox PC et al. Cross-sectional and longitudinal analyses of stimulated parotid salivary constituents in healthy different aged subjects. J Gerontol 1993;48:M219-224.

100. Ship JA, Nolan NE, Puckett SA. Longitudinal analysis of parotid and submandibular salivary flow rates in healthy, different-aged adults. J Gerontol 1995;50A:M285-289.

101. Atkinson JC, Fox PC. Salivary gland dysfunction. Clin Geriatr Med 1992;8:499-511.

102. Hughes CV, Baum BJ, Fox PC et al. Oral-pharyngeal dysphagia: A common sequela of salivary gland dysfunction. Dysphagia 1987;4:101-105.

103. Caruso AJ, Sonies BC, Atkinson JC, Fox PC. Objective measures of swallowing in patients with primary Sjogren's syndrome. Dysphagia 1989;4:101-105.

104. Loesche WJ, Bromberg J, Terpenning MS et al. Xerostomia, xerogenic medications and food avoidances in selected geriatric populations. J Am Geriatr Soc 1995;43:401-407.

105. Gibson G, Barrett $E$. The rolc of salivary function on oropharyngeal coloni zation. Spec Care Dentist 1992;12:153-156. 